\title{
Dios Papá / Dios Mamá: cristianismo liberacionista en el área de mujeres de Frontera Comalapa, México
}

\author{
Deus Pai / Deus Mãe: cristianismo libertador na área \\ feminina de Frontera Comalapa
}

\section{Father God / Mother God: liberating Christianity in the female area of Frontera Comalapa}

\author{
iD Enriqueta Lerma Rodríguez \\ Universidad Nacional Autónoma de México, San Cristóbal de Las Casas, Chiapas, \\ México \\ elermaro@unam.mx
}

(iD) Adriela Pérez Pérez

Centro de Investigaciones y Estudios Superiores en Antropología Social-Unidad Sureste, San Cristóbal de Las Casas, Chiapas, México adri_sol87@hotmail.com

Resumen: El artículo analiza las manifestaciones políticas, culturales y rituales de una expresión del cristianismo liberacionista en el contexto fronterizo Chiapas-Guatemala. Partimos de una conceptualización antropológica de la praxis que permite disertar sobre la acción de las mujeres católicas de la Parroquia Santo Niño de Atocha de Frontera Comalapa, perteneciente a la Diócesis de San Cristóbal de Las Casas, Chiapas. La reflexión está centrada en la experiencia transformadora del área de mujeres, tomando en cuenta no sólo los aportes clásicos de la teología de la liberación y sus vínculos con las ciencias sociales, sino también abordando los nuevos postulados teológicos liberacionistas que exigen nuevos acercamientos teórico-metodológicos para comprender las concreciones contemporáneas del catolicismo latinoamericano.

Palabras clave: Cristianismo liberacionista. Antropología. Praxis. Mujeres católicas. Chiapas. 
Resumo: O artigo analisa as manifestações políticas, culturais e rituais de uma expressão do cristianismo libertador no contexto da fronteira entre Chiapas e Guatemala. Partimos de uma conceituação antropológica da práxis, que nos permite falar sobre a ação de mulheres católicas da Paróquia da Santa Criança de Atocha, em Frontera Comalapa, pertencente à Diocese de São Cristóvão de Las Casas, Chiapas. A reflexão centra-se na experiência transformadora da área das mulheres, levando em conta não só as contribuições clássicas da teologia da libertação e suas ligações com as ciências sociais, mas também os novos postulados teológicos liberacionistas que exigem novas abordagens teórico-metodológicas para compreender as ações concretas contemporâneas do catolicismo latino-americano.

Palavras-chave: Cristianismo liberacionista. Antropologia. Práxis. Mulheres católicas. Chiapas.

Abstract: The article analyzes the political, cultural and ritual manifestations of an expression of liberating Christianity in the Chiapas-Guatemala border context. We start from an anthropological conceptualization of praxis that allows us to speak about the action of Catholic women from Santo Niño de Atocha, Frontera Comalapa, belonging to the Diocese of San Cristóbal de Las Casas, Chiapas. The reflection is centered on the transformative experience of the female area, taking into account not only the classical contributions of liberation theology and their links with the social sciences, but also addressing the new liberationist theological postulates that demand new theoretical-methodological approaches to understand the contemporary achievements of Latin American Catholicism.

Keywords: Liberating Christianity. Anthropology. Praxis. Catholic women. Chiapas.

Data de recebimento: 31/07/2019

Data de aceite: 20/09/2019 
Dios Papá / Dios Mamá: cristianismo liberacionista en el área de mujeres... Enriqueta Lerma Rodríguez • Adriela Pérez Pérez

\section{Introducción}

Sin duda, el impacto de la teología de la liberación y del cristianismo liberacionista ha arrojado interesantes reflexiones sobre la potencialidad de las creencias religiosas como motores del sentido de la acción; un sentido que tiene por principio -en aspiración de sus continuadores- cuestionar la realidad social y generar nuevas prácticas de trasformación en la arena pública desde la fe. Sin embargo, poco se ha dicho de las posibilidades que han abierto a la resignificación de la vida cotidiana en las personas y de sus contextos inmediatos. Con la intención de mostrar este aspecto, cabe aquí resaltar la importancia que cobra el sentido numinoso en la construcción de la praxis cultural e individual de los sujetos creyentes. En el caso que aquí tratamos, situado en un municipio fronterizo de México, en límite internacional Chiapas-Guatemala, se observan estas cuestiones. Se trata de una opción católica nutrida desde distintos imaginarios sociales: del cristianismo liberacionista, de la teología de la liberación, de la raíz indígena maya, de la promoción del buen vivir, de la búsqueda de la equidad de género, de la defensa de lo que se ha denominado "Madre Tierra" y de la necesidad de construir lazos comunitarios en respuesta a un espacio cuyo tejido social se encuentra desdibujado, resultado de la ágil dinámica de migración que experimenta.

A través de estas páginas mostraremos, de manera panorámica, la forma en que se ha resignificado el cristianismo entre los católicos de la parroquia Santo Niño de Atocha de Frontera Comalapa, en especial desde el trabajo de las mujeres, quienes -empoderadas desde la organización eclesial-se suman a diversas tareas colectivas con el interés de transformar su vida personal y su contexto inmediato. Nuestra reflexión -en este artículo en particular- sigue el interés de abonar a la discusión que nos congrega en este dossier: distinguir conceptualmente entre teología de la liberación y cristianismo liberacionista, aplicado al análisis de un caso. En esta tarea, en primera instancia, retomamos las aportaciones de Michael Löwy y de Enrique Dussel -quienes mantienen una 
Dios Papá / Dios Mamá: cristianismo liberacionista en el área de mujeres... Enriqueta Lerma Rodríguez • Adriela Pérez Pérez

discusión cercana-, y sumamos al debate el concepto de praxis de Adolfo Sánchez Vázquez. A estas notas conceptuales dedicamos la primera parte del artículo, con el fin de definir nuestro marco teórico y de argumentar en pos de una clara distinción. Más adelante, para una mejor comprensión de nuestro caso de estudio, exponemos la trayectoria de conformación del proyecto posconciliar en Chiapas, su efecto en un grupo de creyentes que inauguraron el equipo pastal Chicomalapa y los retos que enfrentaron en sus procesos de consolidación. Más tarde, abordamos las problemáticas actuales de Frontera Comalapa y la organización interna de la parroquia de Santo Niño de Atocha. En el siguiente apartado, abordamos el trabajo de las mujeres y los marcos de sentido que configuran su acción social como participantes del cristianismo liberacionista, tanto a nivel individual como colectivo.

Los resultados que aquí ofrecemos son producto del trabajo de campo que hemos realizado en el municipio de Frontera Comalapa de 2014 a 2018; período en que logramos hacer observaciones directas, mantener conversaciones informales, aplicar entrevistas a profundidad sobre temas puntuales y acompañar actividades de distintas pastorales, en especial entre quienes forman parte del área de mujeres. Otros trabajos, resultado de esta investigación en campo son: Los otros creyentes. Territorio y teopraxis de la Iglesia liberadora en la región Fronteriza de Chiapas (LERMA, 2019) y Otras voces des de la frontera Chiapas-Guatemala: praxis, teologías y mujeres católicas en Frontera Comalapa (PÉREZ, 2019).

\section{Sobreteología dela liberación, cristianismoliberacionista y praxis}

Michael Löwy, en su célebre libro Guerra de dioses. Religión y política en América Latina (1999), expuso diferencias cronológicas, conceptuales y de orden entre teología de la liberación y cristianismo liberacionista. Si no lo hemos mal interpretado, la explicación que ofrece permite situar la primera tendencia como 
Dios Papá / Dios Mamá: cristianismo liberacionista en el área de mujeres... Enriqueta Lerma Rodríguez • Adriela Pérez Pérez

un cuerpo de texto eruditos, escritos por distintos teólogos latinoamericanos, resultado de las reflexiones en torno a las innovaciones que acarreó el Concilio Vaticano II (1962-1965), tanto en las reuniones preparatorias -organizadas por la Conferencia Episcopal Latinoamericana (Celam), principalmente en Medellín (1968) y Puebla (1979)- como en los documentos generados por el propio Concilio. En palabras de Löwy, producto de estas discusiones, la teología de la liberación tomaría auge años después: en la década de 1970, a partir del texto célebre de Gustavo Gutiérrez, Teología de la liberación, que le dio nombre. Siguiendo a Löwy, la obra inauguró un nuevo proceso de reflexión, que se apoyó en las teorías y métodos de las ciencias sociales, para construir una teología crítica; meta en la que pusieron empeño numerosos teólogos especializados, interesados en la renovación de los creyentes y en ofrecer una nueva doctrina.

Por otra parte, Löwy encuentra que, previo a la teología de la liberación, se habían generado entre distintos grupos de creyentes diversas praxis que antecedieron a los nuevos escritos teológicos y que iban más allá de lo establecido tradicionalmente en la Iglesia católica formal. Como parte de estas expresiones el autor señala la Acción Católica, la Juventud Universitaria Católica, a los Jóvenes Obreros Cristianos, las redes pastorales y las Comunidades Eclesiales de Base; éstas últimas impulsoras, a su vez, de clubes femeninos, de asociaciones vecinales, de sindicatos obreros y campesinos (LÖWY, 1999, p. 47). Lo que Löwy encuentra en estos movimientos, ajenos a las discusiones teológicas, es su capacidad de inventiva, de organización y de praxis; e indica que, sin la existencia de éstos, promovidos desde la organización popular, no podríamos explicarnos fenómenos históricos como el surgimiento de un nuevo movimiento obrero en Brasil, la revolución centroamericana o las transformaciones sociales en Chiapas (LÖWY, 1999, p. 47). Löwy propuso llamar a este conjunto de expresiones, movimientos y acciones, inspiradas en la fe, y que superan la sola reflexión teológica, como cristianismo liberacionista: 
Dios Papá / Dios Mamá: cristianismo liberacionista en el área de mujeres...

Ya que ese concepto es más amplio que "teología" o de "Iglesia", e incluye tanto la cultura religiosa como la red social, la fe y la praxis. Decir que es un movimiento social no significa necesariamente que sea un cuerpo "integrado" y “bien coordinado", sino sólo que tiene, como todo otro movimiento semejante (el feminismo, la ecología, etc.), una cierta capacidad de movilizar a las personas alrededor de metas comunes. (LÖWY, 1999, p. 48).

Coincidimos en la caracterización que ofrece Löwy para distinguir estas dos corrientes que, aunque cercanas, responden a distintos procesos y a distintos actores. Encontramos, por nuestra parte, que esta separación coincide con la definición de Enrique Dussel (2007), quien distingue entre Teología de la Liberación 1 (TL1) y Teología de la Liberación 2 (TL2). En la primera, TL1, refiere a la hermenéutica y praxis sistematizadas por Gustavo Gutiérrez (1972) y otros teólogos; la cual coincide con la reflexión sobre teología de la liberación que anota Löwy. En la segunda, TL2, Dussel hace referencia a la interpretación de las Escrituras y de los "signos de los tiempos" que surge de las condiciones sociales próximas a los creyentes y de la situación de injusticia que coloca a las personas, a ciertos fenómenos o elementos del mundo, en calidad de víctimas (explotación económica, empobrecimiento social, discriminación racial, inequidad de género, desterritorialización forzada, militarización de la cotidianidad y de los territorios). Ambos autores coinciden, según nuestra mirada, en ver en la teología de la liberación una fase del pensamiento teológico latinoamericano, situado en el análisis de la espiritualidad, es decir, en una praxis filosófica; mientras que el cristianismo liberacionista y la TL2 abarcan un espectro que supera la intelectualidad y espiritualidad teológicas para dar paso a la reflexión sobre la capacidad de los sujetos o víctimas de liberarse desde una praxis de la fe, según su contexto, sus motivaciones y sus metas.

Consideramos que la diferencia profunda entre teología de la liberación y cristianismo liberacionista (o TL2) es la praxis, por ello es necesario ahondar en lo que entendemos por este concepto. 
Dios Papá / Dios Mamá: cristianismo liberacionista en el área de mujeres... Enriqueta Lerma Rodríguez • Adriela Pérez Pérez

Según nuestra opinión, la praxis mantiene una clara herencia con el pensamiento marxista, ya que fue construido en el marco del análisis de la lucha de clases y a partir del contexto industrial alemán, y privilegia un sujeto particular: el proletariado. Pero notamos que, para el caso latinoamericano, la filosofía de la praxis marxista ha sido recuperada por autores cuyos aportes reflejan un potencial analítico para otras realidades. Resalta el trabajo de Adolfo Sánchez Vázquez (2014) y de Dussel (1983, 1998, 2014, 2016), donde el concepto mantiene el principio de acción como transformación: cambio tanto de pensamiento como de la realidad, aún en sujetos que no mantienen un posicionamiento de clase. La cual no puede comprenderse sin abordar tres elementos analíticos concatenados: teoría, sujeto y realidad; aspectos que reflejan un movimiento de carácter dialéctico en su sentido articulador; este tipo de praxis permite la transformación de la teoría, del hombre y de la realidad cultural que lo constituye. Esta triada, en el plano epistemológico, posibilita aproximarse a la lógica de pensamiento que permite comprender la forma en que se construye tanto el conocimiento como la práctica política. Visto así, el análisis de la praxis se convierte en un abanico de posibilidades, en el que pueden ser colocados distintos sujetos, realidades y marcos de sentido.

Para el estudio de nuestro caso es fundamental rescatar esta vinculación (sujeto-teoría-realidad) porque nos permite proponer una perspectiva antropológica de la praxis, es decir, resaltar que en distintos contextos y por variados sujetos, la praxis se construye de diversos aspectos y con diferentes objetivos, que configuran lo que aquí denominamos la noción de marco de sentido. Partimos de la hipótesis de que la praxis del cristianismo liberacionista de Frontera Comalapa se ha construido a partir de aspectos específicos histórico-sociales, de nociones religiosas resignificadas, de acciones particulares que responden a su contexto y que buscan solucionar problemáticas situadas en un lugar específico, así como de metas valoradas colectivamente para la transformación de la realidad próxima. Enfatizamos aquí como 
Dios Papá / Dios Mamá: cristianismo liberacionista en el área de mujeres... Enriqueta Lerma Rodríguez. Adriela Pérez Pérez

sujeto transformador, praxeológico, a las mujeres, para dar cuenta de sus experiencias y reelaboraciones (ahora sí) a nivel teológico y en el plano de su realidad, para situar en su justo nivel de realidad su acción trasformadora. Bajo esta tesitura, cabe preguntarnos qué elementos subyacen en el marco de sentido de las mujeres de Frontera Comalapa, qué observables nos permiten comprender la configuración de su cristianismo liberacionista. Consideramos que la praxis de estas mujeres no sólo se sitúa en el nivel de construirse como agentes de su propia acción, sino también como detonadoras de nuevas reflexiones a nivel teológico y de la práctica religiosa, pero más allá: con el interés de incidir en su contexto social desde la organización eclesial.

En resumen, el concepto de praxis en los autores señalados proporciona claves epistemológicas para articular dialécticamente aspectos fundamentales que permiten pensar la acción transformadora, desde una perspectiva antropológica. Por lo que nos permite proponer algunos elementos para el abordaje de la praxis de las mujeres católicas, insertas en una institución católica ubicada en un contexto fronterizo del sur de México.

Los puntos señalados nos permiten completar la forma en que abordamos el análisis de praxis, es decir, desde un enfoque cultural que nos acerque a una interpretación etnográfica del cristianismo liberacionista, con base en la acción social de las laicas católicas que participan en la pastoral de área de mujeres. Nuestra propuesta subraya la necesidad de dar cuenta del marco de sentido que orienta la praxis de estas creyentes: del sistema heredado como parte de un grupo cultural y de un espacio geográfico; aspectos que se mantienen unidos y que se requiere abordar para comprender la acción como transformación. Por otra parte, para este trabajo la praxis deberá ser entendida a nivel de escalas, tomando en cuenta que no todas las transformaciones se manifiestan en forma radical; algunas son personales y permanecen en el plano individual, pero otras -la mayoría- le superan e inciden en la colectividad. 


\section{Raíces del cristianismo liberacionista en Frontera Comalapa}

En el contexto de Chiapas, el movimiento cristiano liberacionista se implementó en la Diócesis de San Cristóbal de Las Casas, Chiapas, durante el obispado de Samuel Ruiz (1960-2000). Asumimos que se trató de un cristianismo liberacionista que tuvo como germen la discusión y la acción al interior de las comunidades indígenas, a partir del análisis de la realidad y de su deseo de transformarla. A diferencia de otros actores de la misma diócesis, quienes construyeron sus reflexiones a partir de su realidad, Samuel Ruiz sí tuvo cercanía con la teología de la liberación desde sus inicios, de la que fue, además, un gran exponente. Ésta se puede rastrear en su destacada participación en el Concilio Vaticano II y en las Celam de Medellín y Puebla, en los que expuso sobre la importancia de reconocer la inculturación del evangelio y se declaró en favor de respetar la diversidad cultural. El grueso de sus colaboradores, agentes de pastoral (monjas y catequistas), en cambio, habían construido sus principios doctrinales y praxeológicos, principalmente a partir de la observación y experimentación de las necesidades del pueblo chiapaneco, a las que también Samuel Ruiz era sensible.

El sistema de exclusión de que eran sujeto los indígenas en Chiapas desató en el obispo el deseo de construir una nueva pastoral, centrada en coadyuvar en la solución de sus problemas económicos, sociales, de discriminación, explotación y desigualdad. Dicha pretensión se reflejó en dos momentos históricos significativos: en el Congreso Indígena de 1974 y en la Asamblea Diocesana de 1975. El primer evento, organizado inicialmente para que los indígenas celebraran el natalicio de Fray Bartolomé de Las Casas (primer obispo de Chiapas), superó las expectativas de sus organizadores: los indígenas tomaron la tribuna y desde ésta expusieran, a través de cinco ponencias, sus contrariedades: ausencia de servicios de salud, injusticia, falta de 
Dios Papá / Dios Mamá: cristianismo liberacionista en el área de mujeres... Enriqueta Lerma Rodríguez • Adriela Pérez Pérez

acceso a educación, violencia, invasión de tierras y corrupción por parte de funcionarios estatales (VALTIERRA, 2012; MORALES, 2005). El Congreso significaría, en los años sucesivos, el punto de partida de múltiples organizaciones y movilizaciones campesinas en todas las regiones indígenas de Chiapas. El segundo evento: la primera Asamblea Diocesana fue otro parteaguas, en ella se proclamó "la opción preferencial por los pobres" (MORALES, 2005, p. 145), lo que marcó un nuevo viraje en la pastoral. En sintonía con esta opción, Samuel Ruiz desapareció el Consejo Presbiteral (máxima instancia de decisión diocesana), restó importancia a la figura de párroco y colocó en su lugar a equipos pastorales, compuestos por sacerdotes, religiosas y laicos, en igualdad de circunstancias, al frente de las parroquias.

En este contexto, y buscando la renovación eclesial, Samuel Ruiz encontró pertinente poner énfasis en una pastoral indígena, por ello una de las tareas más importantes fue organizar el territorio diocesano en siete regiones etnolingüísticas: Ch'ol, Chab, Tsotsil, Tseltal, Centro, Sur y Sureste, particularizadas según principios culturales y geográficos. El objetivo era desarrollar un mejor trabajo de intervención en las comunidades. La zona pastoral sureste quedó integrada por once parroquias y dos misiones, en ocho municipios: La Trinitaria, La Independencia, Frontera Comalapa, Chicomuselo, Las Margaritas, Tzimol, Comitán y Maravilla Tenejapa.

Frontera Comalapa participó poco de aquel proceso de reorganización diocesano al ser uno de los últimos municipios en recibir atención pastoral. Hasta antes 1979 -año en que se formó el primer equipo parroquial- apenas era visitado anualmente por el sacerdote de una localidad vecina: Zapaluta. De modo que en Frontera Comalapa inició el trabajo posconciliar cuando en otras regiones ya estaba muy avanzado. Otros equipos de otras zonas habían organizado cajas de ahorro, cooperativas de producción y de consumo, clases de alfabetización y cursos de leyes agrarias; habían organizado movimientos sociales en demanda de tierra y contaban con catequistas especializados en distintos campos. 
Dios Papá / Dios Mamá: cristianismo liberacionista en el área de mujeres... Enriqueta Lerma Rodríguez • Adriela Pérez Pérez

En el primer equipo parroquial de Frontera Comalapa participaron algunas monjas de la Compañía de María y algunos sacerdotes maristas, quienes tuvieron a su cargo dos parroquias: Santo Niño de Atocha, en Frontera Comalapa, y San Pedro y San Pablo, en el municipio de Chicomuselo, por este motivo el primer equipo se hizo llamar "Chicomalapa". Éste se propuso, en principio, consolidar un método de trabajo colectivo que les permitiera desatar la reflexión sobre la dignificación de las personas, la lucha por la tierra y la búsqueda de justicia social. El eje de acción se centró, sin embargo, en la lucha agraria por lo que las primeras expresiones colectivas buscaron solucionar demandas del sector campesino. Se promovió la incorporación de la feligresía a organizaciones campesinas, desde las que se exigía indemnización por ocupación de tierras, créditos a la producción y al comercio, así como la ampliación de la propiedad ejidal. Para los catequistas, agentes de pastoral y laicos, participantes en este proceso, esta lucha representó un espacio de formación política y de organización social inigualables. El marco de sentido de su praxis tenía dos ejes articuladores: la opción preferencial por los pobres y la construcción de justicia social en la Tierra, la cual, en efecto, cobraba realidad en la medida en que se tuviera oportunidad de acceder a los terrenos agrícolas y a su producción.

Pero este equipoy la comunidad que les acompañó atravesaron, además, otras coyunturas que les permitieron resignificar su credo y su praxis. Desde su fundación debieron asumir tareas que superaban el ámbito local, regional y hasta nacional; una de ellas fue -en respuesta a una preocupación de Samuel Ruizla formación de un comité de apoyo al refugio guatemalteco. Su creación se anticipó, desde 1979, al arribo de miles de personas que llegaron en los primeros años de la década de 1980. Los refugiados huían de las campañas de exterminio -conocidas como "tierra arrasada"- implementadas por el ejército guatemalteco. Las masacres -ordenadas por el gobierno del país vecino- buscaban eliminar a activistas, organizaciones políticas y grupos guerrilleros, opuestos a los sucesivos gobiernos militares. Las víctimas eran, 
Dios Papá / Dios Mamá: cristianismo liberacionista en el área de mujeres... Enriqueta Lerma Rodríguez - Adriela Pérez Pérez

en su mayoría, campesinos, principalmente indígenas de habla kanjobal, chuj y mam.

Antes de que la Comisión Mexicana de Ayuda a Refugiados y el propio Alto Comisionado de las Nacional Unidas para los Refugiados se hiciera cargo del caso, la Diócesis de San Cristóbal de Las Casas ya contaba con el Comité Cristiano de Solidaridad para acoger a los guatemaltecos en los municipios fronterizos. Los miembros de la iglesia liberadora de Comalapa que colaboran en él se capacitaron en las localidades de Paso Hondo, Comitán y San Cristóbal, bajo asesoría de agentes de pastoral que encabezaban el comité. El refugio duró, en casi todos los casos, más de quince años, período en el que el contacto cotidiano permitió un nutrido intercambio de experiencias entre católicos y allegados. Los guatemaltecos incorporaron de la organización diocesana algunas estrategias de organización comunitaria (cajas colectivas de ahorro, cooperativas productivas, talleres de oficios, reuniones de discusión sobre problemas agrarios, cursos de alfabetización, lectura popular de la Biblia). Los campesinos católicos de Comalapa, por su parte, asimilaron que las demandas políticas y sociales, principalmente agrarias, superaban los intereses locales; confrontarlos iba más allá de una acotada resistencia contra grupos de poder regionales; supieron que para lograr sus objetivos implicaba enfrentar una lucha en contra de un sistema social mundial y estructural: el capitalismo. $Y$ vieron, en la experiencia de los refugiados, que la clase pudiente podía usar todo tipo de prácticas violentas para conservar sus privilegios. En voz de los guatemaltecos conocieron que la lucha por la tierra y otras demandas suponían poner en riesgo la vida.

Ambos procesos: la lucha por la tierra y el refugio guatemalteco, fueron semilleros de experiencias organizativas para los cristianos liberacionistas de Frontera Comalapa. Sin embargo, estos compromisos menguaron tras el asesinato de los líderes del movimiento agrario de la región y con el retorno guatemalteco, promovido a partir de 1994. A la postre la organización eclesial se vio dividida por posicionamiento políticos encontrados, que 
Dios Papá / Dios Mamá: cristianismo liberacionista en el área de mujeres... Enriqueta Lerma Rodríguez • Adriela Pérez Pérez

dieron como resultado el resquebrajamiento de la organización parroquial. El punto definitivo de ruptura fue la desarticulación de la organización campesina el 10 de enero de 1995, cuando fuerzas represivas del estado desmontaron previamente un intento campesino de tomar el palacio municipal. La falla de este golpe se valoró negativamente por una parte de la feligresía católica, que acusó a los creyentes participantes, especialmente a los sacerdotes, de haber orquestado la toma del palacio y de su fracaso. La medida había sido tomada inspirada en la recuperación de tierras del Ejército Zapatista de Liberación Nacional (EZLN), levantado un año antes. La comunidad católica de Comalapa se dividió en dos grupos: los que se asumían continuadores del proyecto posconciliar y quienes lo rechazaron tajantemente. Este suceso fue el inicio de una larga trayectoria de división al interior de la comunidad parroquial, que hasta hoy continúa.

El trabajo conjunto del equipo Chicomalapa se dividió de manera definitiva en el año 2000, cuando, tras jubilarse Samuel Ruiz, su sucesor, el obispo Felipe Arizmendi, decidió reconocer dos parroquias independientes: la del Santo Niño de Atocha en Frontera Comalapa y la de San Pedro y San Pablo en Chicomuselo. Esta separación supuso una renovación de esfuerzos para la feligresía de ambos municipios, quienes, de pronto, encontraron divididas todas sus comisiones, áreas pastorales e instancias eclesiales. Desde entonces, aunque cercanas geográficamente, se encuentran desvinculadas y privilegiando sus propios proyectos.

Pero, ¿qué había pasado con la organización de las mujeres en todo este tiempo? Según testimonios de algunas religiosas que trabajaron en el equipo pastoral Chicomalapa, en aquellos años las mujeres habían construido un proceso de reflexión sobre sí mismas. Habían discutido su triple situación de opresión: sujetas a sus padres, hermanos o maridos; sin reconocimiento de su jornada de trabajo en el campo y a cargo de hogares empobrecidos, donde -en muchos casos- sufrían violencia por parte de un esposo alcohólico. Con este análisis, y para superar su situación, organizaron talleres en los que discutían sus propios 
Dios Papá / Dios Mamá: cristianismo liberacionista en el área de mujeres... Enriqueta Lerma Rodríguez - Adriela Pérez Pérez

problemas, que eran, además de los anteriores, poca participación en la toma de decisiones comunitarias, nula instrucción escolar, falta de acceso a servicios de salud, desnutrición de sus hijos. Reconocieron en grupo su condición social de género, la necesidad de luchar por sus derechos y por la dignificación de sus trabajos; el derecho a vivir sin violencia y a no ser obligadas a casarse con quienes no querían.

En el proceso de construcción de autoconciencia, algunas actoras claves de aquella experiencia identifican dos etapas que corresponden a dos generaciones de monjas: la primera representada por las fundadoras de la Compañía de María (19791994) y la segunda por las religiosas que llegaron después de 1994, cuando las primeras habían dejado Chicomalapa y se habían sumado al retorno de los refugiados. Una de las precursoras narra que al principio buscaron desarrollar un método de trabajo centrado en "ver la realidad, del modo como ven las mujeres la realidad": buscaban textos en el evangelio que las iluminaran y les levantaran el ánimo (María Elena, entrevista de 2017). Era un método sencillo, pero que, como ellas mismas señalan, permitió a muchas mujeres expresar sus opiniones con base en la Biblia. Señalan también que con ayuda de este método -dirigido a leer las Escrituras "a la luz de los tiempos"-, desde una perspectiva de género y con base en el análisis del contexto próximo, muchas adeptas desarrollaran un grado de reflexión importante. Se trataba de impulsar en las laicas la confianza de hablar; de despertar conciencia sobre la importancia de su participación en el mundo; de afianzar la unidad entre ellas en el ámbito local y municipal; así como buscar que la lucha de las mujeres se diera de manera conjunta con la de los hombres para incidir en el cambio de las estructuras opresoras (Parroquia de San Pedro y San Pablo, 1989, p. 2).

La segunda generación incentivó su participación de 1996 hasta 2001, a través de la puesta en práctica de un plan de trabajo al que Ilamaron Proyecto Educativo Juana de Lestonnac, inspirado en aquella teología feminista (LÓPEZ, 2005): una apuesta que 
Dios Papá / Dios Mamá: cristianismo liberacionista en el área de mujeres... Enriqueta Lerma Rodríguez • Adriela Pérez Pérez

apuntaba a superar la formación espiritual, tomando como eje la solidaridad con la sociedad y privilegiando la educación para las mujeres a través de talleres de formación política. En estos talleres las mujeres analizaron cómo se organizaba el sistema electoral, la importancia de emitir un voto razonado y de defender su elección, pero también la necesidad de construir procesos autonómicos para el desarrollo de sus comunidades.

La organización del área de mujeres en Frontera Comalapa no fue aislada, tenía símil en todas las demás parroquias, de modo que el trabajo pastoral en cada equipo se coordinó con el trabajo de otras zonas pastorales. En cada sitio el trabajo adquirió características propias de acuerdo a las diferentes realidades sociales, pero siempre bajo los lineamientos del proyecto posconciliar de la Diócesis de San Cristóbal. En la zona sureste el trabajo con las creyentes tuvo un proceso de transición histórica, trazado con las reflexiones entre laicas y religiosas. De acuerdo con un informe de 1989, elaborado por las religiosas que trabajaron en la zona sureste, para ese año los grupos de mujeres habían proliferado de manera importante en distintos municipios: Chicomuselo (288 mujeres), Comalapa (195 mujeres), Trinitaria (63 mujeres), Comitán (70 mujeres) y la Independencia (75 mujeres). Para 1992 ya se había consolidado la Coordinación Diocesana de Mujeres (Codimuj), espacio donde integrantes de las zonas Ch'ol, Chab, Tsoltsil, Tseltal, Centro, Sur y Sureste se congregaron para abordar su situación desde una perspectiva de género. Es importante recalcar que, aunque Samuel Ruiz conociera su situación, fueron las religiosas quienes desarrollaron el trabajo con sus congéneres, para iniciar una praxis de liberación mutua. Una acción importante y necesaria, ya que ni el Concilio Vaticano II, ni la Celam de Medellín retomaron ampliamente la condición de las mujeres. Bajo esa limitación, el trabajo de las integrantes del área de mujeres y de la Codimuj fue y es relevante en tanto constituye un espacio renovador dentro de la Diócesis de San Cristóbal de Las Casas. 
Dios Papá / Dios Mamá: cristianismo liberacionista en el área de mujeres... Enriqueta Lerma Rodríguez • Adriela Pérez Pérez

En resumen, en Frontera Comalapa fue de gran importancia el impulso de la diócesis, y lo sigue siendo para las mujeres, pues en su área parroquial siguen construyendo reflexiones y propuestas de organización colectiva, tal como veremos en adelante.

\section{Frontera Comalapa en la actualidad}

Antes de adentrarnos en la organización parroquial y su pastoral, es importante señalar algunos aspectos del contexto social en derredor de la parroquia del Santo Niño de Atocha, de modo que permita al lector comprender su especificidad. Frontera Comalapa cuenta con 67,012 habitantes (INEGI, 2010) y presenta clima cálido-húmedo. El municipio forma parte de la región económica XI sierra Mariscal, caracterizada por cultivo de café, cacahuate y maíz, y la cría de ganado, pero también por la intensa actividad comercial; se ubica en la región fronteriza de Chiapas, a poco más de 20 kilómetros de la línea internacional con Guatemala.

Algunas características actuales tienen origen en el periodo de refugio: su arribo condujo al endurecimiento de la política migratoria con el objetivo de marcar la frontera, lo que aumentó los cuerpos de vigilancia. Hoy en día es visible el aumento de militares y de agentes del Instituto Nacional de Migración, así como de policías federales, municipales y de la patrulla fronteriza, a cargo de la seguridad y de la contención poblacional en la frontera ChiapasGuatemala. Esto se corresponde con el aumento de la migración hondureña, guatemalteca y salvadoreña, principalmente, que, en el intento por llegar a Estados Unidos, se topan con los controles migratorios, quedando varados en el municipio de Frontera Comalapa, lo que marca considerablemente la vida cotidiana de los pobladores locales. Desde la mirada de los oriundos, los migrantes mantienen un estatus social ambiguo, son considerados víctimas de la violencia económica o del hostigamiento de las autoridades mexicanas; como mano de obra barata o como insumo humano 
Dios Papá / Dios Mamá: cristianismo liberacionista en el área de mujeres... Enriqueta Lerma Rodríguez - Adriela Pérez Pérez

de las bandas delincuenciales. Por otro lado, la inmigración no sólo es internacional, se nutre también de pobladores de comunidades aledañas. Dichos migrantes se ocupan en el comercio informal, vendiendo aguas, dulces y comida, y complejizan aún más la vida cotidiana que se teje entre los pobladores, quienes se sienten invadidos y con desconfianza.

Al incremento de cuerpos de vigilancia y a la migración se suma la venta de drogas, aspecto señalado por los habitantes, quienes identifican el patrón de distribución mediante el uso de motocicletas, las cuales se escuchan a altas horas de la noche. La venta de drogas y la migración son causa -o pretexto- de que en las vías de comunicación que conectan a Frontera Comalapa con otras localidades (como Comitán o Motozintla) la policía municipal y algunos militares realicen retenes carreteros constantemente para revisar transportes públicos y autos particulares.

En años recientes, otra política implementada por los gobiernos federal y estatal en la región ha sido el extractivismo: la "flexibilidad de las leyes mexicanas para otorgar permisos a las concesiones, México es por segundo año consecutivo el cuarto lugar mundial y el primero de América Latina en atracción a los capitales destinados a la exploración" (ÁNGELES, 2013, p. 293). Los recursos invertidos en la exploración de territorios comunitarios han llevado a descubrir "110 nuevas localidades con potencial minero" (ÁNGELES, 2013, p. 293), algunos ubicados en Chiapas. Estos proyectos de extracción en la frontera han causado contaminación del medio ambiente, fractura del tejido social y despojo de tierras. Un caso concreto es Chicomuselo, afectado por la extracción minera, y cuya feligresía ha mantenido una ágil resistencia en la que participan las comunidades eclesiales de base. La cercanía con Chicomuselo ha conducido a la participación política-religiosa católica de los comalapences, quienes se suman a los foros en defensa de la tierra; espacios donde se denuncian los efectos negativos de la extracción minera y la violación a los derechos de las comunidades. 
Dios Papá / Dios Mamá: cristianismo liberacionista en el área de mujeres... Enriqueta Lerma Rodríguez • Adriela Pérez Pérez

Dicho lo anterior, se comprende la complejidad y conflictividad del contexto en que se ubica la Parroquia Santo Niño de Atocha: un espacio que padece los estragos del incremento del control fronterizo, del paso de productos del narcotráfico, del hacinamiento de cientos de migrantes desempleados y subempleados, de la falta de servicios adecuados y de la conflictividad entre distintos grupos de pobladores, ya sea por posicionamientos políticos o religiosos.

\section{Organización interna en la parroquia Santo Niño de Atocha}

Es importante apuntar que no todos los creyentes católicos, adscritos a esta parroquia, han caminado bajo la línea pastoral posconciliar: existen grupos opositores como Renovación Carismática y la Congregación de Flaviano Amatulli, “los apóstoles de la palabra, defensores de la fe"; grupos que convergen en un mismo espacio, que se vuelve conflictivo y refleja la resistencia de un sector a la transformación doctrinaria posconciliar.

Aun con los bemoles propios del contexto fronterizo y al interior de la feligresía católica, la parroquia sigue trabajando en tratar de solucionar sus conflictos, y para ello ha desarrollado sus pastorales bajo tres líneas: profética, social y litúrgica, que a su vez se subdividen en otros espacios, que contemplan diversos aspectos y buscan atender a sujetos específicos: presos, migrantes, enfermos, niños o mujeres. La línea profética integra ocho áreas: catequesis infantil, catequistas de comunidades, equipo bíblico, presacramental, teología india, pastoral juvenil, comunidades eclesiales de base y pastoral familiar. La línea social agrupa siete pastorales: migrante, penitenciaria, de mujeres, pueblo creyente, salud, derechos humanos y de la Tierra. En liturgia se adscriben: coros, ministros, liturgia y monaguillos.

Desde 1982, y hasta la actualidad, la iglesia del Santo Niño de Atocha se ha organizado territorialmente en cinco zonas pastorales 
Dios Papá / Dios Mamá: cristianismo liberacionista en el área de mujeres... Enriqueta Lerma Rodríguez - Adriela Pérez Pérez

parroquiales: Cabecera (con 18 comunidades), Comalapa (con 18 comunidades), Lajerío (con 11 comunidades), Paso Hondo (con 20 comunidades) y Norte (con 17 comunidades), las que suman 84 comunidades, dividida a su vez en 17 sectores. Cada una de estas entidades cuenta con representación en el Consejo Pastoral parroquial: dos consejeros por cada zona, dos por cada sector y dos por parte de agentes de animación pastoral. Estos 46 consejeros constituyen el núcleo de la organización parroquial en el municipio (Parroquia del Santo Niño de Atocha, 2016). Dicha estructura, aunque compleja, promueve una ágil movilidad de los feligreses, quienes pueden participar en más de un espacio; la movilidad a través de estos permite la comunicación entre distintos hermanos, hombres y mujeres comprometidos con la parroquia.

Por otra parte, la parroquia Santo Niño de Atocha ha tenido transformaciones estructurales positivas a lo largo de su historia, gracias a la movilidad de sus adeptos y a la proliferación de tareas. La descentralización de la figura del sacerdote, quien no conduce todo el trabajo, permite la distribución de las actividades entre laicos y laicas en las distintas áreas. El trabajo que realizan los creyentes actualmente se inspira en los principios trazados en el III Sínodo Diocesano, convocado en 1994 por el obispo Samuel Ruiz García, y puesto en marcha a partir del siguiente año. Su relevancia fue que su documento final fue resultado de la reflexión colectiva de todas las zonas pastorales. La notabilidad de dicho sínodo fue su apertura a escuchar y a tomar en cuenta otras voces: de laicos, religiosas y catequistas. El III Sínodo, además, se postuló por construir procesos de transformación social y de justicia social; con este objetivo, la Diócesis se definió a sí misma en el documento como una iglesia liberadora.

La iglesia liberadora, además de perseguir la construcción del reino de Dios en la Tierra, lo cual indica la búsqueda de justicia, la eliminación de la explotación y la pobreza, como resultado de la opción preferencial por los pobres, ha implicado una praxis que cuestiona la hermenéutica doctrinal tradicional. En casi toda la diócesis, los equipos parroquiales se han tomado en serio el 
Dios Papá / Dios Mamá: cristianismo liberacionista en el área de mujeres... Enriqueta Lerma Rodríguez - Adriela Pérez Pérez

reconocimiento de la inculturación del evangelio, por lo que en su mayoría -entre ellos el de Frontera Comalapa- ha asumido la teología india maya como una forma de reivindicar las raíces culturales ancestrales. En particular en Comalapa se trata de población étnicamente no caracterizada como mayense, pero los participantes del proyecto posconciliar encuentran en el fomento de la teología india maya la posibilidad de construir una identidad local que les permite vincularse con el resto de las parroquias que sí cuentan con población indígena. También intentan, a través de ésta, construir un eje común que articule las distintas pertenencias identitarias: entre habitantes oriundos, inmigrantes regionales y centroamericanos. Con estos objetivos, los adscritos al área de teología india en Comalapa, donde trabajan de manera sobresaliente varias mujeres, innovan su trabajo promoviendo el "rescate" de las tradiciones, de los saberes de "las abuelas y los abuelos" y la historia de la localidad.

Elimpacto dela teología indiamaya en lafeligresía comalapence se puede observar en las innovaciones de la fiesta patronal del pueblo, cuando el Santo Niño de Atocha -casi siempre colocado en un altar con forma de mazorca de maíz- es llevado en peregrinación hasta una casa donde se le hace una ceremonia, al lado del altar circular maya (compuesto con flores, pétalos y semillas de la región). En estos espacios, las mujeres son quienes actúan como vehículos de la tradición: encargadas de colocar el altar, de dirigir palabras a los asistentes, de convocar a las entidades del tzolkin maya y de organizar círculos de diálogo sobre los sentires de los asistentes.

Porotraparte, lasmujerescristianas liberacionistas deComalapa se han propuesto el resignificar los puntos medulares del credo católico, asumiendo la reinterpretación de un dios androcéntrico -varón y patriarcal-, hacia un Dios papá / Dios-mamá. De modo que es común escuchar en los encuentros de distintas áreas discursos donde la noción de lo divino asume una dimensión andrógina. Pero dios no sólo es reinterpretado con cualidades de mujer en el sentido llano del término: dios es madre; de ahí que la noción de 
Dios Papá / Dios Mamá: cristianismo liberacionista en el área de mujeres... Enriqueta Lerma Rodríguez • Adriela Pérez Pérez

Madre Tierra tome un tinte divino como dadora de la vida. Dios Madre / Madre Tierra son el eje de gran parte de la organización posconciliar y en su defensa se ha construido toda una resistencia social en defensa del medio ambiente. Es de suma importancia este viraje hermenéutico, pues de él se desprende la posibilidad de que las mujeres participen en igualdad de circunstancias en los trabajos eclesiales, pero también las movilizaciones sociales a que se suma la parroquia. A esta reformulación se han opuesto otros católicos de la misma parroquia, quienes defienden una visión más tradicional y oficial de la iglesia y del credo. La praxis liberadora de estas mujeres católicas, de este modo, se encuentra siempre en constante tensión con otros católicos, quienes no comparten la idea de cuestionar, y menos aún la de reinterpretar su credo religioso. Además de esta oposición, los católicos más oficialistas también rechazan la participación de estas mujeres en la liturgia, pues, a diferencia de otros espacios católicos (la gran mayoría), en el pulpito de esta parroquia las mujeres sí pueden predicar.

Lo dicho hasta aquí muestra el modo en que se ha relaborado la estructura eclesial de la parroquia del Santo Niño de Atocha para servir al contexto social en que está inmersa, así como su resignificación doctrinal, resultado de una praxis que se ha propuesto no solo actuar en las transformaciones sociales y del espacio público, sino también al interior de la doctrina y de la hermenéutica católica, donde las mujeres asumen una nueva significación y diversas formas de agencia. Ahora pasemos a ver el modo en que esta apuesta posconciliar, actualizada, particularizada y específica del cristianismo liberacionista toma sentido en un par de mujeres de manera individualizada. Aunque los cristianos liberacionistas constituyan un sujeto social colectivo, por otro lado, estamos conscientes de que cada persona se dirige personalmente a partir del marco de sentido que ha construido y que desde éste dirige su praxis. 


\section{Mujeres y praxis cristiana liberacionista: marcos de sentido}

En este punto de nuestro análisis nos parece pertinente mostrar algunos datos sobre el tipo de praxis del cristianismo liberacionista, según el marco de sentido de algunas creyentes católicas de la Parroquia Santo Niño de Atocha. En los siguientes párrafos mostraremos las reflexiones que les han permitido promover la transformación colectiva, base para consolidar un frente común de conocimiento y de trabajo. Sin embargo, tal como veremos, a nivel de la praxis se reflejan particularidades interpretativas teológicas en cada laica, con base en sus parámetros culturales y a partir de su experiencia personal. La caracterización de estas praxis se aborda desde el marco analítico de Löwy, Dussel y Sánchez Vázquez, como de la perspectiva teórica de dos autoras del pensamiento feminista poscolonial: Saba Mahmood (2008) y Chandra Tapalde Mohanty (2008). La importancia de traer su propuesta en esta etapa del escrito responde a que no podemos explicarnos la experiencia transformadora de las laicas y sus interpretaciones teológicas sin considerar que su agencia está constituida a partir de su condición de género y a partir de sus biografías personales, pero sobre todo de las interpretaciones que han dado a su credo religioso.

Mahmood propone una antropología particular que permita conocer las aspiraciones, los deseos, las motivaciones y los compromisos del sujeto para entender la importancia de su práctica. Según esta perspectiva, adentrarse en las personas permite estar atentos a las acciones y discursos cuestionadores, que desde una mirada radical pueden parecer intranscendentes, pero que en conjunto expresan movimientos internos del sujeto y de la colectividad. Tapalde Mohanty, por su lado, centra su análisis en la categoría "mujeres", invitando a no caracterizarlas como un grupo homogéneo: con intereses, deseos y formas de significar la vida cotidiana de manera idéntica, sino como individuos marcados por diferencias de clase y de status cultural. Los dos enfoques 
Dios Papá / Dios Mamá: cristianismo liberacionista en el área de mujeres... Enriqueta Lerma Rodríguez - Adriela Pérez Pérez

invitan a poner atención tanto en lo colectivo como la especificidad de cada parte que le constituye. Acercarnos a estas autoras, según hemos convenido, nos permite apreciar la praxis de las mujeres como resultado de sus distintas trayectorias, subjetividades y aspiraciones; de ahí su utilidad.

Las mujeres de quienes aquí hablaremos para ejemplificar la construcción de la praxis liberacionista católica son Carmen y Marcela. Carmen tiene 64 años; es casada y madre de siete hijos. Tres aún permanecen solteros y viven con ella. Para cumplir de manera eficiente en la iglesia ha tenido que cuestionar su papel como ama de casa y concientizar a su familia de la importancia de participar en la dinámica social colectiva. Cada día Carmen debe organizar su vida doméstica y así contar con tiempo para dedicar al área de mujeres, en la que ha sido representante por once años. Su trabajo inició con el equipo Chicomalapa, entonces todavía coordinado por la primera generación de sacerdotes que llegaron a la parroquia. Se formó con las religiosas de la Compañía de María (las monjas Martina, María Elena, María Luisa y Lolis). Antes de insertarse en el trabajo eclesial no era creyente, pero en 1990 se convirtió al catolicismo. En su infancia y adolescencia creció en un ambiente familiar de arrieros, desde entonces, según narra, aprendió a trabajar con animales: "a mí me llevaban a cargar las bestias y allí aprendí a hablar con malas palabras" (Entrevista, 2016).

Carmen no fue a la escuela, y más tarde no logró adquirir la lectoescritura. Desde pequeña aprendió en su entorno familiar a obedecer a sus padres, sin cuestionar nada, de modo que al vivir violencia doméstica durante su matrimonio contó con pocos recursos emocionales para hacer frente al abuso. Pero su vida cambió en el periodo de Chicomalapa, al lado de las religiosas: "Desde esos años empecé a liberarme de todo lo que me esclavizaba. Aprendí que podía decir no a lo que la pareja quiere" (Carmen, entrevista 2016). Las religiosas la incluyeron en los grupos de mujeres donde aprendió, junto con sus congéneres laicas, que los hombres no eran los únicos que podían "dar su 
Dios Papá / Dios Mamá: cristianismo liberacionista en el área de mujeres... Enriqueta Lerma Rodríguez • Adriela Pérez Pérez

palabra" dentro de la Iglesia. Aunque al principio sintiesen miedo y vergüenza, empezaron a compartir sur reflexiones, posteriormente adquirieron mayor seguridad al hablar en público. El trabajo de Chicomalapa fue muy importante para Carmen y otras mujeres, en reuniones especiales para ellas reflexionaron sobre su situación: "Vimos que sufríamos con cargas de trabajo; en salud, veíamos como las mujeres nos enfermábamos más. Nosotros teníamos que ver por nuestros derechos y perder la vergüenza al participar en las reuniones, porque la mayoría eran hombres" (Carmen, entrevista 2016).

Hoy en día trabaja en colaboración con Marcela en el área de mujeres. Marcela tiene cuarenta y ocho años y es madre de cuatro hijos; es coordinadora de grupo de mujeres del sector tres, donde cuenta con cuatro años de experiencia; además, forma parte del grupo de ministros. Inició su trabajo con el actual párroco. Marcela subsiste económicamente de vender atole por las mañanas en el mercado y desempeña otros trabajos remunerados en su domicilio, como preparar comida y lavar ropa. Al igual que ella, la mayoría de las mujeres de la parroquia son comerciantes y combinan esta actividad con otras que les permitan completar sus ingresos.

Marcela siempre ha sido católica; su praxis dentro de la iglesia se intensificó en colaboración con el párroco actual. Reconoce que años atrás no realizaba su trabajo con entusiasmo; pero considera que no ha sido la única que trabajó con desgano; aún ahora identifica que en la parroquia hay muchos espacios en los que se pueden desempeñar cargos, pero que no todos asumen el compromiso. Se identificó plenamente con el equipo parroquial y con un compromiso genuino -lo que llama estar "adentro de la parroquia"- cuando inició su participación como ministra, como catequista de niños y en el área de mujeres. A partir de su participación en el área de mujeres descubrió que la Coordinación Diocesana de Mujeres realizaba actividades en San Cristóbal de manera regular y asumió las actividades como un espacio propio: "Me distraigo y al mismo tiempo aprendo. Los quehaceres del hogar nos van desgastando con tanto trabajo que hacemos, en cambio, 
Dios Papá / Dios Mamá: cristianismo liberacionista en el área de mujeres...

al estar en la palabra de Dios nos alimenta el corazón, fortalece el alma, nos motiva a salir adelante, tanto en las cosas de la casa, como en nuestra vida personal". Su participación en los eventos de San Cristóbal, asegura, le ayuda en el aspecto emocional, familiar y en su crecimiento personal: "Me ayuda porque si tengo coraje, al ir con las hermanas se me pasa; estar con ellas leyendo la palabra de Dios, 'con ojos, mente y corazón de mujer', nos ayuda, para que nosotras, que estamos en el hogar, no acabemos enfermas haciendo el trabajo. Salir cambia tu estado emocional y te fortalece" (Marcela, entrevista 2016).

Tanto Carmen como Marcela asisten regularmente a las reuniones y cursos de formación de la Coordinación Diocesana de Mujeres. En este espacio discuten, al lado de otras mujeres de otras zonas pastorales, temas sobre cuestiones políticas, económicas, culturales y religiosas, bajo tres enfoques: mística, género y análisis de la realidad. Estas reuniones, Ilamadas "de análisis", les permiten reflexionar sobre su situación como laicas, insertas en diversos contextos que conducen a situaciones específicas. Las reflexiones que realizan en la Codimuj más tarde son compartidas en el área de mujeres de la parroquia y después se traducen acciones concretas para Frontera Comalapa: "Nosotras decimos que es importante que veamos el análisis de la realidad, porque no tiene que quedarse únicamente escrito, sino que tenemos que tomar compromiso para incidir en lo que sucede en nuestro entorno" (Carmen, entrevista 2017).

Con relación a lo político, se analiza el resultado que ha tenido la aplicación de programas de gobierno a nivel local. Por ejemplo, se señala que "los gobiernos engañan a las personas con programas de ayuda". Como muestra se menciona el programa federal de inclusión social Prospera (que otorga ayuda de alimentación, salud y educación, así como apoyo a proyectos productivos): se crítica que el dinero otorgado forma parte de los impuestos que cada ciudadano paga, pero que los apoyos se condicionan a cambio de la lealtad de los ciudadanos hacia los partidos políticos: 
Dios Papá / Dios Mamá: cristianismo liberacionista en el área de mujeres...

Enriqueta Lerma Rodríguez - Adriela Pérez Pérez

Ese dinero es nuestro, por eso les digo a las mujeres que si van a recibirlo que los reciban, pero que no se queden calladas antes las injusticias de los políticos. Que no dejen de participar en las peregrinaciones o manifestaciones. Pero no pasa eso [para seguir siendo leales]: cuando dieron las televisiones, ese día aquí estuvo lloviendo, y como los grupos de mujeres tuvimos reuniones [...] de regreso pasamos donde estaban recibiendo sus famosas televisiones, y ahí vi a muchas mujeres esperando bajo la lluvia y el sereno. Entonces, ¿por qué cuando el gobierno ofrece algo ahí van todas y todos, y cuando se trata de cuestionar las injusticias vemos poca participación? (Carmen, entrevista 2017).

Respecto al tema de género -con un lenguaje sencillo, ejemplos claros y cotidianos- las mujeres del área de mujeres enfatizan en distinguir conceptualmente género de sexo; y hacen uso de estas categorías para describir las actividades y roles que se asignan culturalmente a hombres y mujeres, bajo una perspectiva machista:

Tampoco vamos diciendo que el género es todo. El género es lo que aprendimos, lo que nos enseñaron nuestros papás. Por ejemplo, al niño se le dice que puede ir a jugar y a la niña que cuide de su hermanito. Entonces tenemos que enseñar al niño que los dos tienen que trabajar. Esto solo se logrará si lo reflexionamos entre las hermanas y al saber los que nos perjudica ellas puedan ir enseñando de otra forma a sus hijos e hijas. (Carmen, entrevista 2016).

Con relación a lo que denominan como mística, analizan algunos textos bíblicos desde una perspectiva de género: "desde la realidad que viven como mujeres". Como ejemplo refieren al pasaje del evangelio de San Marcos sobre la mujer que "tenía hemorragia", aquella que sanara tras tocar el manto de Jesús. Desde aquella referencia reflexionan: “En aquel tiempo esa mujer fue curada, en nuestro tiempo, ¿qué nos cura? Ahora no podemos 
Dios Papá / Dios Mamá: cristianismo liberacionista en el área de mujeres... Enriqueta Lerma Rodríguez • Adriela Pérez Pérez

ir a tocar el manto de Jesús, pero podemos ir a la iglesia porque allá está Jesús sacramentado. Las que no podemos ir a otros lugares y conocer otras cosas, podemos buscar lugares cercanos que nos den sanidad" (Marcela, entrevista 2017). Sus reflexiones, sin embargo, no se limitan a la idea de tradicional del milagro involuntario de Jesús; desde su perspectiva, la mujer sangrante se curó porque confío en su propia fe, en su propia capacidad para alcanzar la sanación, aún sin que Jesús se lo hubiese propuesto.

Otro pasaje de la Biblia que se ha erigido como referente es Lucas 13:10-17. En éste se habla de "la mujer encorvada", quien llevaba dieciocho años enferma sin poder enderezarse y sanó en un encuentro con Jesús. Con base en este episodio interpretan que muchas mujeres se encuentran humilladas y pisoteadas: "es un texto que ayuda a pensar en la situación en que viven muchas mujeres de algunas comunidades, bajo la humildad y dominio del hombre" (Marcela, entrevista 2017).

Si bien muchos aspectos de la vida cotidiana de estas mujeres se han transformado, es de mencionar el compromiso que han desarrollado a nivel de la acción en el espacio público. Pese a las condiciones de inseguridad que vive Frontera Comalapa, las mujeres están presentes en las manifestaciones y peregrinaciones en las que se demanda la solución de los problemas municipales. En específico, entre las mujeres, es continua la exigencia del cierre de cantinas, identificadas como la causa del incremento de la violencia doméstica; por ello colaboran en la redacción de documentos y pronunciamientos, dirigidos a la presidencia con este fin: "En el municipio reflexionamos sobre la situación que vivimos, especialmente el alcoholismo; de ahí vienen todos los problemas, porque el alcoholismo y la drogadicción son dos cosas que matan y hay violencia, porque por medio de eso se golpea a la mujer"(Carmen, entrevista 2016).

Nos sobra señalar también que estas mujeres se suman a las numerosas manifestaciones multitudinarias que se realizan el 8 de marzo, Día Internacional de la Mujer; a las peregrinaciones del Pueblo Creyente en momentos en que es necesario hacer 
Dios Papá / Dios Mamá: cristianismo liberacionista en el área de mujeres... Enriqueta Lerma Rodríguez - Adriela Pérez Pérez

presencia pública en la defensa de los derechos humanos o por la libertad de presos políticos; que participan activamente en los foros y mítines que se convocan en defensa de la Madre Tierra y contra el extractivismo. Pero también que adecúan sus motivaciones y metas a partir del contexto social, de modo que se encuentran en la búsqueda constante de innovar sus estrategias y dispuestas a relaborar su doctrina, si es necesario.

Con base en lo anterior, es posible decir que la praxis de estas mujeres dentro de la parroquia les ha dado seguridad. Como se observó en el caso de las creyentes aquí abordado, ambas encontraron en el área de mujeres un lugar para repensar la situación de opresión en que se encuentran; un lugar para liberarse de las relaciones desiguales que se construyen entre hombres y mujeres. Su praxis se expresa en sentido individual y político, orientada a la transformación de la situación en que se encuentran. Su marco de sentido, como creyentes, se amplió: mantienen la idea de que desde la iglesia liberadora nadie debe ser esclavo de alguien más. Por otra parte, pretenden ir más allá al cuestionar la opresión que viven las mujeres en la propia iglesia: señalan que las esposas de los diáconos también deben ser nombradas como tales. En resumen, las praxis de las laicas no se pueden entender sin el entramado cultural en el que viven, que va desde relaciones familiares, profesionales, contextuales, eclesiales y por los marcos de sentido que han adquirido dentro de la parroquia, que las lleva a incidir en los distintos escenarios.

\section{Algunos comentarios finales sobre esta iglesia liberadora}

La compleja trayectoria de formación de la Iglesia liberadora en Frontera Comalapa y el extenso trabajo que realizan en sus numerosas áreas hace imposible abordarlos en las limitadas páginas de este artículo. Tratamos, por nuestra parte, de mostrar una panorámica sucinta de lo que ha sido el proceso de formación del trabajo pastoral en la parroquia del Santo Niño de Atocha, 
Dios Papá / Dios Mamá: cristianismo liberacionista en el área de mujeres... Enriqueta Lerma Rodríguez. Adriela Pérez Pérez

con el interés de exponer el camino y sentido que ha tomado el proyecto posconciliar en este espacio. Encontramos que, aunque el principal exponente y promotor de este trabajo, el obispo Samuel Ruiz, sí tuvo como eje de su formación la influencia de la teología de la liberación, de la que fue parte, al menos en esta comunidad, los agentes de pastoral, los miembros del equipo pastoral y los participantes de las distintas áreas pastorales, construyeron sus reflexiones y su praxis a partir de su trayectoria histórica y de los retos que debieron enfrentar en sus contextos inmediatos. Tomando como base la disertación de Löwy sobre cristianismo liberacionista, encontramos que, en efecto, en esta parte de la frontera con Guatemala, el trabajo de los católicos comprometidos con la opción posconciliar ha configurado su credo y sus prácticas religiosas a partir de sus experiencias y de sus propias reflexiones. Esto no niega el hecho de que la literatura de algunos teólogos de la liberación ha sido conocida por algunos creyentes, pero su número no es significativo.

Consideramos que en el caso de las mujeres, sin embargo, sí han impactado las ideas de algunas teólogas feministas, pero también es de señalar que se desconoce el nombre de quienes las han producido. En ese sentido, los saberes sobre la condición de las mujeres se asumen como producto de la reflexión colectiva. Bajo esta tesitura, para las católicas liberacionistas, sus reformulaciones son resultado de su propia forma de ver el mundo, de interpretar la realidad y de significar su credo religioso.

\section{Referencias}

ÁNGELES, Lucero. Extracción minera de barita en Chicomuselo, Chiapas, México. En: DELGADO, Gian (coord.). Ecología política del extractivismo en América Latina: y casos de resistencia y justicia socioambiental. Buenos Aires: CLACSO, 2013.

DIÓCESIS DE SAN CRISTÓBAL DE LAS CASAS. Cómo se enlazan y coordinan los grupos del Área de Mujeres en la Diócesis de 
Dios Papá / Dios Mamá: cristianismo liberacionista en el área de mujeres... Enriqueta Lerma Rodríguez • Adriela Pérez Pérez

San Cristóbal de Las Casas Chiapas. San Cristóbal de Las Casas: Mimeo, 2013.

DUSSEL, Enrique. Ética de la liberación en la edad de la globalización y la exclusión. Madrid: Editorial Trotta, 1998.

DUSSEL, Enrique. Filosofía de la liberación. México: FCE, 2014. DUSSEL, Enrique. Praxis Latinoamericana y filosofía de la liberación. Bogotá: Editorial Nueva América, 1983.

DUSSEL, Enrique. Transformaciones de los supuestos epistemológicos de la teología de la liberación. En: GONZÁLEZ, Miguel et al. (coord.). Debate actual sobre la Teología de la Liberación. México: Universidad Autónoma MetropolitanaIztapalapa, 2007.

DUSSEL, Enrique. 14 tesis de ética. Hacia la esencia del pensamiento crítico. México: Editorial Trotta, 2016.

GUTIÉRREZ, Gustavo. Teología de la liberación. Perspectivas. Salamanca: Ediciones, 1972.

INEG - Instituto Nacional de Estadística y Geografía. Centro de población y vivienda. Disponible en: http://www.microrregiones. gob.mx/zap/datGenerales.aspx?entra=zap\&ent=07\&mun=034. Consultado el: 2017.

LERMA, Enriqueta. Los otros creyentes. Territorio y tepraxis de la Iglesia liberadora en la Región Fronteriza de Chiapas. México: Universidad Nacional Autónoma de México-Centro de Investigaciones Multidisciplinarias sobre Chiapas y la Frontera Sur, 2019.

LÖWY, Michael. Guerra de dioses. Religión y política en América Latina. México: Siglo XXI, 1999.

LÓPEZ, Gallardo. Actualización del proyecto educativo de Juana de Lestonnac sustentado en su experiencia de salvación en la vivencia de los grupos de mujeres en 
Dios Papá / Dios Mamá: cristianismo liberacionista en el área de mujeres...

Chicomuselo. 2005. Tesis (Licenciatura en Ciencias Teológicas) Seminario Bíblico Latinoamericano, San José de Costa Rica, 2005.

MAHMOOD, Saba. Teoría feminista y el agente dócil: algunas reflexiones sobre el renacimiento Islámico en Egipto. En: SUÁREZ, Liliana; HERNÁNDEZ, Rosalva Aída. Descolonizando el feminismo: teorías y prácticas desde los márgenes. España: Ediciones cátedra/ Universidad de Valencia/ Instituto de la Mujer, 2008.

MORALES, Jesús. Entre ásperos caminos llanos. La diócesis de San Cristóbal de Las Casas 1950-1995. México: UNICACH/ COCITECH/Casa Juan Pablo/UNICH, 2005.

PARROQUIA DE SAN PEDRO Y SAN PABLO. Informe del área de mujeres. Chicomuselo, 1989.

PARROQUIA DEL SANTO NIÑO DE ATOCHA, Reseña de la Parroquia del Santo Niño de Atocha del equipo pastoral sureste de la Diócesis, como preparación a la Visita Pastoral que realizará nuestro padre obispo diocesano, Don Felipe Arizmendi Esquivel, del lunes $\mathbf{1 4}$ al miércoles $\mathbf{1 6}$ de marzo de 2016. Frontera Comalapa: Mimeo, 2016.

PÉREZ, Adriela. Otras voces desde la frontera Chiapas-

Guatemala: praxis, teologías y mujeres católicas en Frontera Comalapa. 2019. Tesis (Maestría en Antropología) - Universidad Nacional Autónoma de México, México, 2019.

SÁNCHEZ, Adolfo. Filosofía de la praxis. México: Siglo XXI, 2013.

TAPALDE, Chandra. Bajo los ojos de Occidente: feminismo académico y discursos coloniales. En: SUÁREZ, Liliana; HERNÁNDEZ, Rosalva Aída. Descolonizando el feminismo: teorías y prácticas desde los márgenes. España: Ediciones cátedra/Universidad de Valencia/ Instituto de la Mujer, 2008.

VALTIERRA, Jorge. En busca de la Iglesia autóctona: la nueva pastoral indígena en las cañadas tojolabales. Liminar, v. X, p. 74-89. Disponible en: http://www.redalyc.org/articulo. oa?id=7425515005. Consultado el: 8 jul. 2015. 